\title{
Formulation and Evaluation of Misoprostal by Chronotherapeutic Drug Delivery System
}

\author{
Musfeera Adeel*, Sana Begum, Shaik Gouse and Shanti Kumar \\ Department of Pharmacy, Vijay college of Pharmacy, Jawaharlal Nehru Technological University, Hyderabad, India
}

Received: June 03, 2016; Accepted: June 28, 2016; Published: June 30, 2016

*Corresponding author: Musfeera Adeel, Department of Pharmacy, Vijay college of Pharmacy, Jawaharlal Nehru Technological University, Hyderabad; Tel no: 0091 9502603303; E-mail: musfeeraadeel@gmail.com

\begin{abstract}
In this present study it has been aimed to develop Spray Coated tablets of Misoprostol with a view of minimizing the drug release in the physiological ecology of stomach and small intestine and to ensure maximum drug release in the colon. This study was conducted to develop colon targeted Misoprostal delivery for the treatment of Colonic Bacterial Infections and to study the influence of coating thickness and ratios of lag time polymers (Eudragit L 100 and Eudragit S 100) on drug release and lag time.
\end{abstract}

\section{Introduction}

Chronotherapy can be defined as the administration of bioactive agent or pharmaceutical products at certain periods of the day that are thought to reduce undesirable adverse effects to increase the drug's desired effects. The study of biological rhythms and their respective mechanisms is known as Chronobiology.

On the basis of biological response of time keeping, the Biological rhythm plays an important role in determining the response of drugs administered at any time of the day [1]. Many approximations have been done, in order to enhance the effectiveness of the drug, one of the method used is Chronotherapeutic Drug delivery system.

These differences can cause changes both in abnormal condition and in plasma drug concentrations. Human circadian rhythm is based on the activity of sleep cycle, human genetic makeup influences the sleep activity cycle and hence, the functions of the body is also affected [2] Chronopharmaceutical Drug Delivery Systems (ChrDDS) can be defined as regardless of the route of administration, the ability of the bio-active compound or therapeutic agent to deliver its desired effects to a patient in a diseased condition and should embody or includes time-controlled and to deliver the drug to specific site $[3,4]$.

The main goal of Drug Delivery Research is to develop formulations in order to meet the therapeutic needs for particular pathological conditions. The importance of Biological Rhythms in chronotherapy has been demonstrated in the research of Chronopharmacological field and this brought a new approach to development of Drug Delivery System [5].

\section{Biological Rhythms}

Biological rhythm are basic characteristic of human life on earth that is explained as Cyclical Activities or self-sustaining oscillation of human and animal origin [9]. The spectrum of biological rhythms is well displayed and understood in Table 1. A great deal of research shows that the inherited period of the human pacemaker clock is not precisely 24 hours [6]. In fact, in most people, it is somewhat longer, closer to 25 hour Figure 1. Environmental times, termed synchronizers or zeitgebers, the strongest one being the daily light-dark cycle occurring in conjunction with the wake-sleep routine, set the inherited pacemaker circadian timekeeping systems to 24 hours each day $[7,13]$.

\section{Cardiac Rhythms}

This is the most common biological rhythm and it deals with biological functions of human which can be represented as such of 24 hours clock and it also alter the sleep-wake cycle Figure 2. The circadian rhythms of serum cholesterol and triglycerides and urinary diuresis crest early in the evening. [8]. The information conveyed in this figure clearly illustrates that the biochemistry and physiology of human beings are not constant; rather, they are variable in predictable and coordinated manner during the $24 \mathrm{~h}[12,13]$.

\section{Chronotherapy}

Coordinating biological rhythms with medical treatment is

\begin{tabular}{|l|l|}
\hline \multicolumn{2}{|l|}{ Table 1: List of materials used: } \\
\hline Name of the material & Source \\
\hline Misoprostol & Natco pharma India. \\
\hline Ethyl Cellulose & Signet Chemical Corporation, Mumbai, India. \\
\hline Eudragit L-100 & Merck Specialities Pvt Ltd, Mumbai, India. \\
\hline Eudragit S-100 & Merck Specialities Pvt Ltd, Mumbai, India. \\
\hline Eudragit RSPO & Merck Specialities Pvt Ltd, Mumbai, India \\
\hline $\begin{array}{l}\text { Hydroxy Propyl Methyl } \\
\text { Cellulose K100M }\end{array}$ & Merck Specialities Pvt Ltd, Mumbai, India \\
\hline Isopropyl alcohol & Universal Chemicals, Hyderabad, India \\
\hline Reagents & \\
\hline Hydrochloric Acid & Universal Chemicals, Hyderabad, India. \\
\hline
\end{tabular}




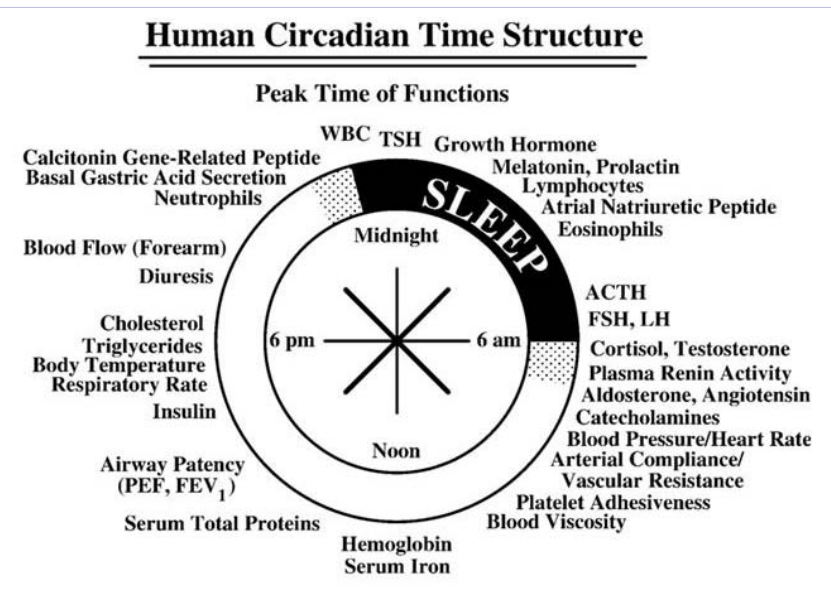

Figure 1: Human circadian time structure. Shown is the approximate peak time of circadian (24-h) rhythms of selected biological variables in persons adhering to a normal routine of daytime activity ( 6-7 a.m. to $\sim 10-11$ p.m.) alternating with nighttime sleep.

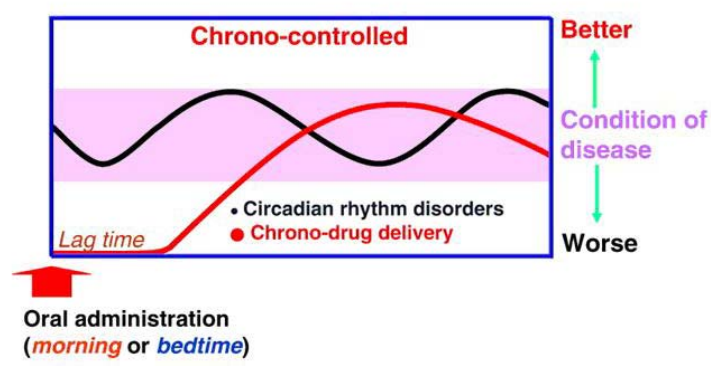

Figure 2: Circadian rhythm of clinical diseases.

known as Chronotherapy, which allows for appropriate dosing of actives at the most suitable times of the day, thus improving efficacy and reducing undesirable side effects $[10,11]$.

\section{Advantages of Chronotherapy:}

- Important advantage of Chronotherapy is that it is drugfree treatment

- Enhancement of Chronotherapy takes places when is a person is sleeping.

- The disease condition and confidence is improved when patients often fall asleep during Chronotherapy.

- Chronotherapy has beginning, middle and an end for the treatment, this makes chronotherapy different from other treatment processes. So it is easily predictable the point at which the treatment works.

- It gives the patient an entire new schedule like waking up earlier and sleeping prior to scheduled time which will be quite unusual for some days but it will give $u$ a period to adjust psychologically [16].

- Chronotherapy improves stability

- Chronotherapy has no risk of dose dumping [19].

\section{Disadvantages of Chronotherapy:}

- A non 24 hour sleep- wake syndrome is developed after the Chronotherapy treatment as sometimes the person sleeps or over 24 hours during the treatment.

- The person will wake up earlier then the scheduled time and he/she will not be able to sleep again.

- Chronotherapy makes the person to become less productive during the therapy and staying awake till the other schedule will be bit uncomfortable.

- It is mandatory to have Medical supervision during this therapy.

- Large number of process variables.

- Manufacturing requires only Trained /skilled person.

\section{Chronotoxicology}

Chronotoxicology is an important aspect of chronodynamics; it refers to the interactions between the toxic substances and biological rhythms [18]. It deals specifically with the rhythmdependent, and refers with the major and minor differences in the indication and severity of adverse effects and the patients suffering with the intolerance to medications or pharmaceutical compound [14]. The high risk of adverse effects and relatively narrow therapeutic range for the classes of medications in particular, are likely to show significant dosing-time differences in safety [17].

When ingested in the morning as a single daily dose at the commencement of the daily activity span, these medications are best tolerated because of their least adrenocortical suppression. Especially in the evening between dinner and bed time, when the moderate daily dose of glucocorticoid is ingested or inhaled late in the day, the risk of adrenocortical suppression is increased [15].

\section{Materials}

$\begin{array}{lll}\text { Drug : } & \text { MISOPROSTOL } \\ \text { Solubility : } & \text { Water soluble }>1.6 \mathrm{mg} / \mathrm{mL} \text { at } 25.0^{\circ} \mathrm{C} \\ \text { Physical State: } & \text { Liquid } \\ \text { Melting point: } & 261-263^{\circ} \mathrm{C}\end{array}$

CAS Registry No.: 62015398

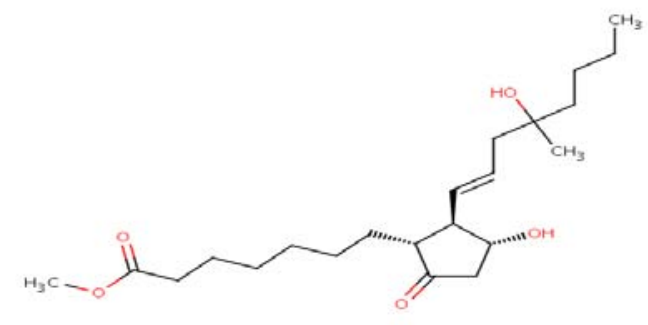




\author{
Molecular formula: $\mathrm{C}_{22} \mathrm{H}_{38} \mathrm{O}_{5}$ \\ Molecularweight: Average:382.5341 , Mono isotopic: \\ 382.271924326
}

Bioavailability: $80 \%-85 \%$

Half-life: 20-40 minutes

Protein binding: $80-90 \%$

Dose : $\quad 100-200 \mathrm{mcg}$

Category:

- Preventing stomach ulcers (duodenal, gastric and NSAID induced)

- Inducing labor

- End a pregnancy (abortion)

- Spontaneous abortion

- Postpartum Hemorrhage (PPH)

- Uterine rupture

The following are the materials and tables used. Table 1 and Table 2

\section{Methods}

\section{Buffers used for Standard calibration curve for Misoprostol}

Preparation of $0.1 \mathrm{~N}$ Hydrochloride: $0.1 \mathrm{~N} \mathrm{HCl}$ is prepared by dissolving $8 \mathrm{ml}$ of Hydrochloric acid (conc.) make upto 1000 ml with Distilled water.

Preparation of simulated Intestinal fluid (pH 7.4 Buffer): Simulated Intestinal Fluid (pH 7.4 Buffer) is prepared by dissolving $50 \mathrm{ml}$ of 0.2M Potassium Dihydrogen Ortho Phosphate and $39.1 \mathrm{ml}$ of $0.2 \mathrm{M}$ Sodium Hydroxide and make the volume upto $200 \mathrm{ml}$ with Distilled water.

Preparation of $6.8 \mathrm{p} \mathrm{H}$ Buffer: By dissolving $50 \mathrm{ml}$ of $0.2 \mathrm{M}$ Potassium Dihydrogen Ortho Phosphate and $22.4 \mathrm{ml}$ of $0.2 \mathrm{M}$ Sodium Hydroxide and make up the volume upto $200 \mathrm{ml}$ with Distilled water gives $200 \mathrm{ml}$ o f pH 6.8 Buffer.

Preparation of $0.2 \mathrm{M}$ potassium Dihydrogen Ortho Phosphate: Dissolve 27.218 o f Potassium dihydrogen ortho phosphate in Distilled water and make up to $1000 \mathrm{ml}$ with Distilled water.

Preparation of 0.2 M Sodium hydroxide: Dissolve 8.0gm of Sodium hydroxide in Distilled water and make up to $1000 \mathrm{ml}$ with Distilled water.

\section{Analytical Method}

Determination of Absorption Maxima: A solution of Misoprostol of concentration $10 \mu \mathrm{g} / \mathrm{ml}$ was prepared in $0.1 \mathrm{NHCl}$, 7.4 $\mathrm{PH} \&$ phosphate buffer 6.8PH respectively, UV spectrum was taken using Double beam UV/VIS spectrophotometer. The solution was scanned in the range of $200-400$.

\begin{tabular}{|c|c|c|}
\hline $\begin{array}{l}\text { Name of the } \\
\text { Equipment }\end{array}$ & Model & Manufacturer \\
\hline Weighing Balance & Dona balance (KM2) & Keroy Scientifics, India. \\
\hline $\begin{array}{l}\text { Tablet Compression } \\
\text { Machine (Multistation) }\end{array}$ & Mini -Press & $\begin{array}{l}\text { Karnavati Engg Pvt } \\
\text { Limited, India. }\end{array}$ \\
\hline Hardness tester & Monsanto & Sisco, Mumbai, India. \\
\hline Vernier callipers & VC03 & Mitutoyo, Japan. \\
\hline Roche Friabilator & FT 1020 & $\begin{array}{l}\text { Lab india , Mumbai, } \\
\text { India }\end{array}$ \\
\hline $\begin{array}{l}\text { Auto Dissolution } \\
\text { Apparatus }\end{array}$ & 8500 & $\begin{array}{l}\text { Lab india , Mumbai, } \\
\text { India }\end{array}$ \\
\hline $\begin{array}{l}\text { UV-Visible } \\
\text { Spectrophotometer }\end{array}$ & UV 3000 plus & $\begin{array}{l}\text { Lab india , Mumbai, } \\
\text { India }\end{array}$ \\
\hline pH meter & PNo.9251117 & $\begin{array}{l}\text { Lab india , Mumbai, } \\
\text { India }\end{array}$ \\
\hline $\begin{array}{l}\text { FT-IR } \\
\text { Spectrophotometer }\end{array}$ & Spectrum 65 & $\begin{array}{l}\text { Per kin Elmer, United } \\
\text { States of America. }\end{array}$ \\
\hline Pharma R\&D Coater & GMP & VJ Instruments limited. \\
\hline
\end{tabular}

Preparation Calibration Curve: For Misoprostol: $10 \mathrm{mg}$ of Misoprostol drug was accurately weighed and dissolved in $10 \mathrm{ml}$ of $0.1 \mathrm{~N} \mathrm{HCl}, 7.4 \mathrm{PH}$, and $6.8 \mathrm{PH}$ in $10 \mathrm{ml}$ volumetric flask , to make $(1000 \mu \mathrm{g} / \mathrm{ml})$ standard stock solution (1). Then $1 \mathrm{ml}$ stock solution (1) was taken in another $10 \mathrm{ml}$ volumetric flask to make $(100 \mu \mathrm{g} / \mathrm{ml})$ standard stock solution (2), then again 1 $\mathrm{ml}$ of stock solution (2) was taken in another $10 \mathrm{ml}$ volumetric flask and then respective concentrations were prepared such as $2,4,6,8,10,12,14,16,18$,and $20 \mu \mathrm{g} / \mathrm{ml}$ with $0.1 \mathrm{~N} \mathrm{HCl}, 7.4 \mathrm{PH}$, and 6.8 PH respectively. The absorbance of standard solution was determined using UV/ VIS spectrophotometer at $273 \mathrm{~nm}$. Linearity of standard curve was assessed from the square of correlation coefficient (r2) which determined by least-square linear regression analysis.

Preparation of Misoprostol core tablets: Each core tablet (average weight $400 \mathrm{mg}$ ) for in vitro drug release studies consist of Misoprostol, Ethyl cellulose, Eudragit RSPO, HPMC K 100 M, HPMC E 15, Talc, Lactose and Magnesium stearate, Dicalcium phosphate (Table 5).The materials were weighed accurately, mixed and passed through a mesh no 60 to ensure complete mixing. The thoroughly mixed materials were then directly compressed into tablets using $12 \mathrm{~mm}$ round, flat punches on a tablet punching machine.

Tablet quality control tests such as weight variation, hardness, friability, thickness, and dissolution in different media were performed on the core tablets Table 3.

Coating of Misoprostol core tablets: The optimized core tablets (F5 and F6) were spray coated with different quantities of coating material containing of Eudragit L 100 and Eudragit S 100 in different ratios such as 1:1, 1:2, 2:1 in different concentrations like $5 \%, 7.5 \%$ with R\&D Coater, VJ Instruments. Tablet quality control tests were performed on the compression coated tablets Table 4.

\section{Evaluation of Tablets}

The designed formulations of core and compression coated 
Misoprostol tablets were studied for their physicochemical properties like weight variation, hardness, thickness, friability and drug content.

Weight Variation Test: To study the weight variation, twenty tablets were taken and their weight was determined individually and collectively on a digital weighing balance. The average weight of one tablet was determined from the collective weight. The mean and deviation were determined. The percent deviation was calculated using the following formula. Table 5

$\%$ Deviation $=$ (Individual weight - Average weight $/$ Average weight) $\times 100$

Hardness: Hardness of tablet is defined as the force applied across the diameter of the tablet in order to break the tablet. For each formulation, the hardness of three tablets was determined using Monsanto hardness tester and the average is calculated.

Thickness: Tablet thickness is an important characteristic in reproducing appearance. Average thickness for core and coated tablets is calculated and presented with deviation Table.

Friability: The mechanical strength of tablets is called as Friability. Roche friabilator was used to determine the friability. Pre weighed tablets were placed in the friabilator. The tablets were rotated at $25 \mathrm{rpm}$ for 4 minutes (100 rotations). At the end of test, the tablets were reweighed; loss in the weight of tablet is the measure of friability and is expressed in percentage as
$\%$ Friability $=[(\mathrm{W} 1-\mathrm{W} 2) / \mathrm{W}] \times 100$

Where,

W1= Initial weight of three tablets

W2= Weight of the three tablets after testing [20,21].

Determination of Drug Content: Both the core tablets and compression-coated tablets of Misoprostol were tested for their drug content. Ten tablets were finely powdered, the quantities of the powder equivalent to one tablet weight of Misoprostol were accurately weighed, and transferred to a $100 \mathrm{ml}$ volumetric flask containing $50 \mathrm{ml}$ water and were allowed to stand to ensure complete solubility of the drug. The mixture was made up to the volume with water. The solution was suitably diluted and the absorption was determined by UV -Visible spectro photometer. The drug concentration was calculated from the calibration curve.

\section{In vitro drug release studies}

Drug release studies of Misoprostol core tablets: The core tablets containing 400mg of Misoprostol were tested in $6.8 \mathrm{pH}$ phosphate buffer solution for their dissolution rates. Dissolution studies were performed using USP dissolution apparatus 2, with50 rpm, at $37 \pm 0.5^{\circ} \mathrm{C}$. At various time intervals, a sample of $5 \mathrm{ml}$ was withdrawn and replaced with equal volume of fresh medium. The samples were analyzed spectrophotometrically at $320 \mathrm{~nm}$.

\begin{tabular}{|c|c|c|c|c|c|c|c|}
\hline \multirow[b]{2}{*}{ SS.NO } & \multirow[b]{2}{*}{ Ingredients } & \multicolumn{6}{|c|}{ Quantity/tablet(mg) } \\
\hline & & \multicolumn{6}{|c|}{ Formulation codes } \\
\hline 11 & Misoprostol & 200 & 200 & 200 & 200 & 200 & 200 \\
\hline 22 & HPMCK 100M & 50 & 100 & - & - & - & - \\
\hline 44 & Ethyl cellulose & - & - & - & - & 50 & 100 \\
\hline 55 & Lactose & 138 & 88 & 138 & 88 & 138 & 88 \\
\hline 66 & Magnesium stearate & 4 & 4 & 4 & 4 & 4 & 4 \\
\hline \multirow[t]{2}{*}{77} & Talc & 8 & 8 & 8 & 8 & 8 & 8 \\
\hline & Total Weight of tablet(mg) & 400 & 400 & 400 & 400 & 400 & 400 \\
\hline
\end{tabular}

Table 4: Composition of coating solution of Coated Tablets

\begin{tabular}{|c|c|c|c|c|c|c|}
\hline \multirow{2}{*}{ Ingredients } & \multicolumn{3}{|l|}{$5 \%$} & \multicolumn{3}{|l|}{$7 \%$} \\
\hline & 1:1 & $1: 2$ & $2: 1$ & 1:1 & $1: 2$ & $2: 1$ \\
\hline Eudragit L 100(mg) & $2.5 \mathrm{mg}$ & $1.7 \mathrm{mg}$ & $3.4 \mathrm{mg}$ & $3.75 \mathrm{mg}$ & $2.5 \mathrm{mg}$ & $5 \mathrm{mg}$ \\
\hline Eudragit S 100(mg) & $2.5 \mathrm{mg}$ & $3.4 \mathrm{mg}$ & $1.7 \mathrm{mg}$ & $3.75 \mathrm{mg}$ & $5 \mathrm{mg}$ & $2.5 \mathrm{mg}$ \\
\hline Isopropyl alcohol(ml) & $90 \mathrm{ml}$ & $90 \mathrm{ml}$ & $90 \mathrm{ml}$ & $87.5 \mathrm{ml}$ & $87.5 \mathrm{ml}$ & $87.5 \mathrm{ml}$ \\
\hline Dibutylthalate(ml) & $1 \mathrm{ml}$ & $1 \mathrm{ml}$ & $1 \mathrm{ml}$ & $1 \mathrm{ml}$ & $1 \mathrm{ml}$ & $1 \mathrm{ml}$ \\
\hline Talc & $0.5 \mathrm{mg}$ & $0.5 \mathrm{mg}$ & $0.5 \mathrm{mg}$ & $0.5 \mathrm{mg}$ & $0.5 \mathrm{mg}$ & $0.5 \mathrm{mg}$ \\
\hline Water(ml) & $3 \mathrm{ml}$ & $3 \mathrm{ml}$ & $3 \mathrm{ml}$ & $3 \mathrm{ml}$ & $3 \mathrm{ml}$ & $3 \mathrm{ml}$ \\
\hline Total (percentage) & 100 & 100 & 100 & 100 & 100 & 100 \\
\hline
\end{tabular}


Table 5: Pharmacopoeial specifications for Tablet Weight Variation.

\begin{tabular}{|l|l|l|}
\hline $\begin{array}{l}\text { Average weight of } \\
\text { tablet (mg) (I.P) }\end{array}$ & $\begin{array}{l}\text { Average weight of } \\
\text { tablet (mg) (U.S.P) }\end{array}$ & $\begin{array}{l}\text { Maximum percentage } \\
\text { difference allowed }\end{array}$ \\
\hline Less than 80 & Less than 130 & 10 \\
\hline $80-250$ & $130-324$ & 7.5 \\
\hline More than & More than 324 & 5 \\
\hline
\end{tabular}

The dissolution results of Misoprostol core tablets in SIF (pH 7.4) solutions were shown in Table. From the above drug release profiles of core tablets it was interpreted that among all the formulations, formulations such as F5and F6 with Ethyl cellulose: Misoprostol ratio (1:2 and 1:4) has shown $91.29 \pm 0.39 \%$ and $94.09 \pm 0.30 \%$ drug release respectively. These were subjected to spray coating using enteric coating polymers such as Eudragit L 100 and Eudragit S 100 [22].

Drug Release Studies of Spray Coated Misoprostol Tablets: The release of Misoprostol from coated tablets was carried out using USP paddle - type dissolution apparatus at a rotation speed of $50 \mathrm{rpm}$, and a temperature of $37 \pm 0.5{ }^{\circ} \mathrm{C}$. For tablets, simulation of gastrointestinal transit conditions was achieved by using different dissolution media. Thus, drug release studies were conducted in simulated gastric fluid (SGF, $\mathrm{pH}$ 1.2) for the first 2 hours as the average gastric emptying time is about 2 hours. Then, the dissolution medium was replaced with enzyme- free simulated intestinal fluid ( SIF, pH 7.4) and tested for drug release for 3hours, as the average small intestinal transit time is about 3 hours, and finally enzyme-free simulated intestinal fluid ( SIF, pH 6.8 ) was used up to 12 hours to mimic colonic $\mathrm{pH}$ conditions [23]

Drug release was measured from spray coated Misoprostol tablets, added to $900 \mathrm{ml}$ of dissolution medium. $5 \mathrm{ml}$ of sample was withdrawn every time and replaced with fresh medium, samples with drawn at various time intervals were analyzed spectro photo metrically at $275 \mathrm{~nm}$ and $270 \mathrm{~nm}$ respectively. All dissolution runs were performed for six batches. The results were given with deviation $[24,25,26]$.

\section{Results}

\section{Analytical Method}

Graphs of Misoprostol was taken in Simulated Gastric fluid (pH 1.2) and Simulated Intestinal Fluid (pH 6.8 and 7.4)

Graph of Misoprostol in $\mathbf{0 . 1 N} \mathbf{H C l}$ (275nm) Table 6 and Figure 3

Graph of Misoprostol in 7.4 pH Simulated Intestinal Fluid (319nm) Graph 1 Figure 4 and Table 7

\section{Preformulation Parameters of Core Material Table 8}

Misoprostol blend was subjected to various pre-formulation parameters. The apparent bulk density and tapped bulk density values ranged from 0.52 to 0.581 and 0.606 to 0.671 respectively. According to Tables 3 and 4, the results of angle of repose and compressibility index (\%) ranged from $32.74 \pm 0.12$ to $37.08 \pm$ 0.96 and $13.37 \pm 0.38$ to $14.72 \pm 0.62$ respectively. The results of angle of repose $(<35)$ and compressibility index $(<23)$ indicates fair to passable flow properties of the powder mixture. These results show that the core powder mixture has good flow properties. The formulation blend was directly compressed to tablets and in-vitro drug release studies were performed.

\begin{tabular}{|l|l|}
\hline Table 6: Observations for graph of Misoprostol in $\mathbf{0 . 1 N} \mathbf{~ H C l}$ \\
\hline Conc. $[\mathbf{m g} / \mathbf{l}]$ & abs \\
\hline 0 & 0 \\
\hline 2 & 0.145 \\
\hline 4 & 0.319 \\
\hline 6 & 0.482 \\
\hline 8 & 0.681 \\
\hline 10 & 0.858 \\
\hline
\end{tabular}

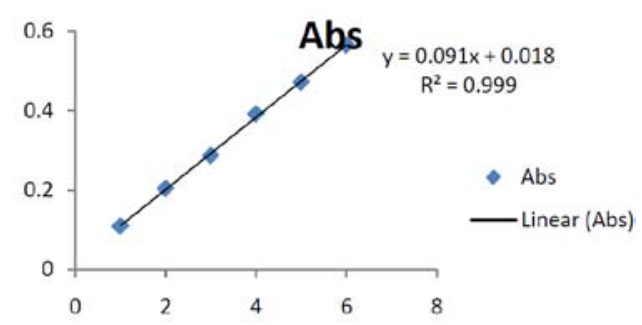

Figure 3: Standard graph of Misoprostol in $0.1 \mathrm{~N} \mathrm{HCl}$.

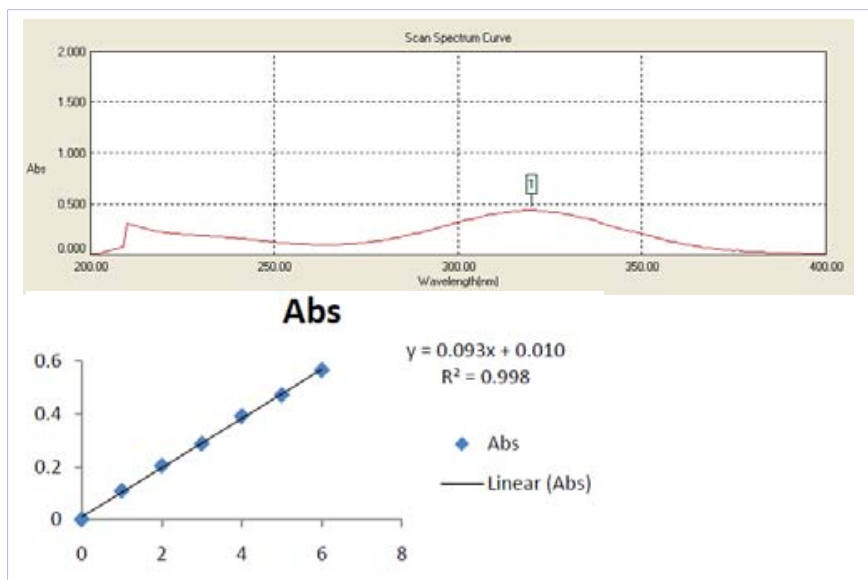

Figure 4: Standard graph of Misoprostol in $7.4 \mathrm{pH}$.

\begin{tabular}{|l|l|}
\hline Table 7: Observations for graph of Misoprostol in $\mathbf{7 . 4} \mathbf{~ p H}$ \\
\hline Conc. $[\mathbf{m g} / \mathbf{l}]$ & Abs \\
\hline 0 & 0 \\
\hline 1 & 0.109 \\
\hline 2 & 0.204 \\
\hline 3 & 0.287 \\
\hline 4 & 0.392 \\
\hline 5 & 0.472 \\
\hline 6 & 0.566 \\
\hline
\end{tabular}




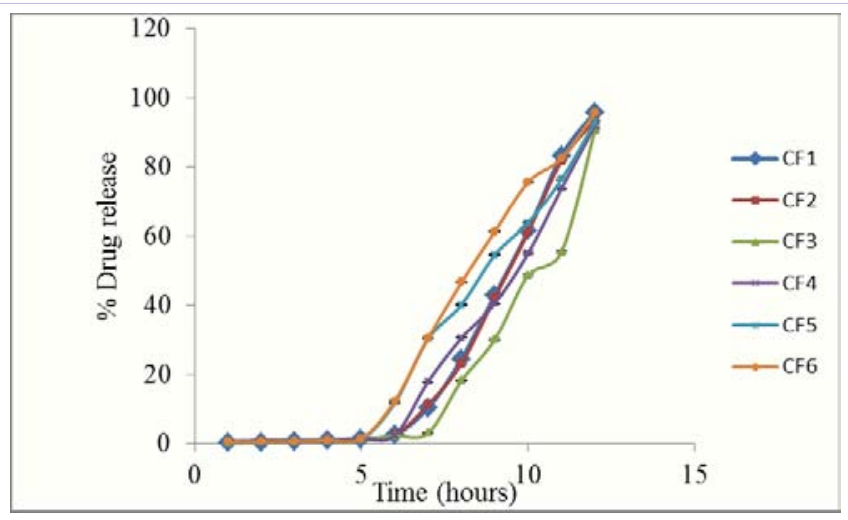

Figure 5: Drug Release Profile of Coated Formulations F1 to F6.

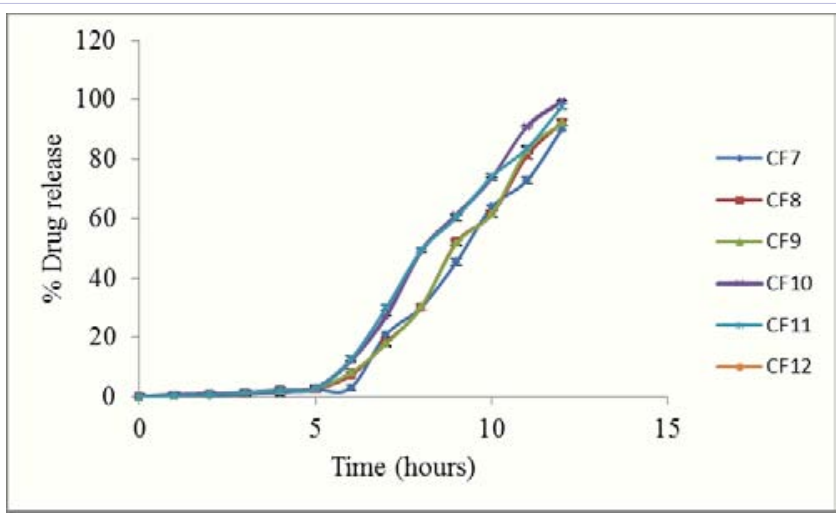

Figure 6: Drug Release Profile of Coated Formulations F7 to F12.

Table 8: Pre-formulation parameters of Core blend

\begin{tabular}{|l|l|l|l|l|l|}
\hline Formulation Code & Angle of Repose & Bulk density $(\mathbf{g m} / \mathbf{m l})$ & Tapped density $\mathbf{( g m} / \mathbf{m l})$ & Carr's index (\%) & Hausner's Ratio \\
\hline F1 & $36.01 \pm 0.62$ & $0.55 \pm 0.27$ & $0.645 \pm 0.13$ & $14.72 \pm 0.62$ & 0.85 \\
\hline F2 & $34.87 \pm 0.06$ & $0.57 \pm 0.18$ & $0.66 \pm 0.09$ & $13.63 \pm 0.12$ & 0.86 \\
\hline F3 & $32.74 \pm 0.12$ & $0.53 \pm 0.22$ & $0.606 \pm 0.04$ & $14.19 \pm 0.26$ & 0.858 \\
\hline F4 & $35.33 \pm 0.62$ & $0.531 \pm 0.31$ & $0.613 \pm 0.03$ & $13.37 \pm 0.38$ & 0.866 \\
\hline F5 & $36.24 \pm 0.05$ & $0.549 \pm 0.14$ & $0.641 \pm 0.17$ & $14.35 \pm 0.54$ & 0.856 \\
\hline F6 & $36.12 \pm 0.45$ & $0.564 \pm 0.32$ & $0.666 \pm 0.11$ & $15.31 \pm 0.22$ & 0.846 \\
\hline
\end{tabular}

\section{Evaluation of Misoprostol Core Tablets}

Misoprostol powder was compressed directly into a core tablet by using direct compression vehicle such as magnesium stearate and talc. The hardness of the core tablets of Misoprostol was found to be in the range of $8.4 \pm 0.1$ to $9.4 \pm 0.21 \mathrm{~kg} / \mathrm{cm}$. The core tablets of Misoprostol were also found to comply with the friability tests in the weight loss was found to be in the range of $0.25 \pm 0.032$ to $0.55 \pm 0.021 \%$. The tablets thickness was found to be in the range of $2.81 \pm 0.022$ to $2.96 \pm 0.043 \mathrm{~mm}$.All formulations were complying with the Indian Pharmacopoeia specifications. Thus the core tablets of Misoprostol formulated in the study were found to have the required characteristics for compression coating with Eudragit L100 and Eudragit S100.
Quality Control Parameters for Core and Coatedformulation Table 9 and Table 10

Evaluation of Misoprostol Coated Tablets: Quality control tests of tablets such as Weight variation $(500.51 \pm 0.16)$, Thickness $(3.78 \pm 0.062)$, Hardness $(6.96 \pm 0.20)$, Friability $(0.26 \pm 0.015)$, Drug content (99.54 \pm 0.27 ) were performed to spray coated Misoprostol tablets and the results were found to be within the Indian pharmacopoeia specifications. Resulted tablets were evaluated for drug release by using USP dissolution apparatus 2. Assay of tablet shown that tablets are of required purity and matches with Indian pharmacopoeial specification.

In-Vitro Drug Release Studies of Misoprostol of Coated

\begin{tabular}{|c|c|c|c|c|}
\hline \multirow{2}{*}{ Formulation codes } & \multicolumn{2}{|c|}{ Weight variation(mg) } & \multicolumn{2}{|c|}{ Hardness $(\mathrm{kg} / \mathrm{cm} 2)$} \\
\hline & Before coating & After coating & Before coating & After coating \\
\hline CF1 & $400.7 \pm 0.77$ & $501.34 \pm 0.56$ & $8.5 \pm 0.1$ & $6.8 \pm 1.08$ \\
\hline CF2 & $399.91 \pm 0.53$ & $500.85 \pm 0.25$ & $8.76 \pm 0.11$ & $6.73 \pm 0.15$ \\
\hline CF3 & $400.34 \pm 0.56$ & $508.11 \pm 0.69$ & $8.23 \pm 0.15$ & $7.26 \pm 0.17$ \\
\hline CF4 & $386.59 \pm 0.72$ & $507.63 \pm .43$ & $8.4 \pm 0.1$ & $6.76 \pm 0.11$ \\
\hline CF6 & $398.11 \pm 0.12$ & $506 \pm 0.01$ & $9.2 \pm 0.11$ & $7.76 \pm 0.11$ \\
\hline CF7 & $400.55 \pm 1.10$ & $500.56 \pm 0.52$ & $9.4 \pm 0.21$ & $7.68 \pm 0.15$ \\
\hline CF8 & $401.34 \pm 0.32$ & $502.67 \pm 0.03$ & $8.4 \pm 0.1$ & $6.4 \pm 0.13$ \\
\hline CF9 & $400.58 \pm 0.52$ & $500.56 \pm 0.77$ & $8.6 \pm 0.3$ & $7.46 \pm 0.11$ \\
\hline CF10 & $399.02 \pm 0.67$ & $500.51 \pm 0.16$ & $8.83 \pm 0.115$ & $6.96 \pm 0.20$ \\
\hline CF11 & $400.56 \pm 0.78$ & $502.91 \pm 0.68$ & $9.1 \pm 0.1$ & $7.63 \pm 0.25$ \\
\hline
\end{tabular}




\begin{tabular}{|l|l|l|l|l|l|}
\hline \multicolumn{6}{|l|}{ Table 10: Quality control parameters for (core and coated tablets) } \\
\hline Formulation codes & $\begin{array}{l}\text { Thickness before } \\
\text { coating } \mathbf{( m m )}\end{array}$ & $\begin{array}{l}\text { Thickness after coating } \\
\text { (mm) }\end{array}$ & $\begin{array}{l}\text { Friability before coating } \\
\text { (\%loss) }\end{array}$ & $\begin{array}{l}\text { Friability after coating } \\
\text { (\%loss) }\end{array}$ & Drug content (\%) \\
\hline CF1 & $2.82 \pm 0.014$ & $3.69 \pm 0.019$ & $0.36 \pm 0.013$ & $0.48 \pm 0.011$ & $99.12 \pm 0.69$ \\
\hline CF2 & $2.83 \pm 0.013$ & $3.66 \pm 0.017$ & $0.31 \pm 0.011$ & $0.35 \pm 0.015$ & $99.26 \pm 1.03$ \\
\hline CF3 & $2.85 \pm 0.016$ & $3.61 \pm 0.033$ & $0.55 \pm 0.021$ & $0.34 \pm 0.015$ & $99.51 \pm 0.59$ \\
\hline CF4 & $2.89 \pm 0.041$ & $3.79 \pm 0.013$ & $0.34 \pm 0.014$ & $0.27 \pm 0.015$ & $98.26 \pm 1.02$ \\
\hline CF5 & $2.87 \pm 0.011$ & $3.77 \pm 0.027$ & $0.29 \pm 0.020$ & $0.36 \pm 0.020$ & $99.51 \pm 0.69$ \\
\hline CF6 & $2.81 \pm 0.022$ & $3.65 \pm 0.036$ & $0.43 \pm 0.011$ & $0.25 \pm 0.030$ & $99.02 \pm 0.59$ \\
\hline CF7 & $2.86 \pm 0.028$ & $3.62 \pm 0.025$ & $0.25 \pm 0.032$ & $0.32 \pm 0.045$ & $99.52 \pm 1.88$ \\
\hline CF8 & $2.91 \pm 0.029$ & $3.73 \pm 0.030$ & $0.34 \pm 0.029$ & $0.38 \pm 0.010$ & $99.09 \pm 0.49$ \\
\hline CF9 & $2.87 \pm 0.038$ & $3.69 \pm 0.045$ & $0.38 \pm 0.016$ & $0.23 \pm 0.020$ & $98.46 \pm 0.67$ \\
\hline CF10 & $2.96 \pm 0.043$ & $3.78 \pm 0.062$ & $0.41 \pm 0.013$ & $0.26 \pm 0.015$ & $99.54 \pm 0.27$ \\
\hline CF11 & $2.89 \pm 0.011$ & $3.81 \pm 0.011$ & $0.37 \pm 0.019$ & $0.33 \pm 0.011$ & $98.13 \pm 0.41$ \\
\hline CF12 & $2.88 \pm 0.036$ & $3.63 \pm 0.028$ & $0.32 \pm 0.021$ & $0.25 \pm 0.035$ & $99.08 \pm 0.52$ \\
\hline
\end{tabular}

\section{Tablets}

The coated tablets containing 500mg of Misoprostol were tested in Simulated Gastric Fluid (pH1.2), Simulated Intestinal Fluid (pH7.4) and for their dissolution rates. Dissolution studies were performed using USP dissolution test apparatus 2, with $50 \mathrm{rpm}$, at $37 \pm 0.5^{\circ} \mathrm{C}$. At various time intervals, a sample of $5 \mathrm{ml}$ was withdrawn and replaced with equal volume of fresh medium. The samples were analyzed spectrophotometrically at $275 \mathrm{~nm}$ and $270 \mathrm{~nm}$ respectively.

In- vitro drug release studies were conducted to the spray coated Misoprostol tablets and drug release studies shown that formulation F10 have shown good release behavior in colon $(99.54 \pm 0.20)$ in 12 hour with limited drug release in stomach and intestine. This indicates that Eudragit L 100 and Eudragit S100 (1:1) in $7.5 \%$ concentration were able to release maximum drug in the colon at 12 hour. This study confirms that Eudragit L 100, Eudragit S 100 act as carrier by using ethyl cellulose as binder to deliver drug to the colon effectively Table 11 and Table 12.

\section{Conclusion}

Eudragit L 100 and Eudragit S 100 (1: 1) in combination $(7.5 \%)$, in the form of spray coating polymers were capable of protecting Misoprostol from being released in the upper region of Gastro Intestinal system, i.e. Stomach and small intestine. The in-vitro drug release studies indicated that formulation CF10 was a promising system to provide targeting of Misoprostol to the colon. There lease pattern of the above formulation was best fitted to Korsmeyer-Peppas model and zero-order model. Mechanism of drug release followed was non-fickian (super case-II) transport mechanism. FT-IR spectrum studies showed that there was no interaction between the drug and excipients. It was concluded that the release lag time and release rate were able to be tailored through adjusting the formulation variable is to achieve Colon Targeting Drug Delivery of Misoprostol.

Table 11: In- vitro Drug Release profile for coated formulations (F1- F6)

\begin{tabular}{|c|c|c|c|c|c|c|}
\hline Time(hrs) & CF1 & CF2 & CF3 & CF4 & CF5 & CF6 \\
\hline 1 & $0.26 \pm 0.23$ & $0.42 \pm 0.24$ & $0.34 \pm 0.24$ & $0.73 \pm 0.28$ & $0.51 \pm 0.11$ & $0.52 \pm 0.18$ \\
\hline 2 & $0.43 \pm 0.26$ & $0.54 \pm 0.21$ & $0.54 \pm 0.33$ & $0.98 \pm 0.22$ & $0.64 \pm 0.19$ & $0.57 \pm 0.29$ \\
\hline 3 & $0.71 \pm 0.29$ & $0.65 \pm 0.27$ & $0.65 \pm 0.26$ & $1.11 \pm 0.17$ & $0.86 \pm 0.24$ & $0.68 \pm 0.33$ \\
\hline 4 & $0.93 \pm 0.37$ & $0.87 \pm 0.1$ & $0.89 \pm 0.18$ & $1.28 \pm 0.31$ & $1.11 \pm 0.35$ & $0.95 \pm 0.20$ \\
\hline 5 & $1.38 \pm 0.35$ & $1.18 \pm 0.23$ & $1.26 \pm 0.32$ & $1.52 \pm 0.17$ & $1.29 \pm 0.16$ & $1.44 \pm 0.12$ \\
\hline 6 & $2.56 \pm 0.33$ & $2.45 \pm 0.16$ & $2.22 \pm 0.17$ & $2.39 \pm 0.27$ & $11.71 \pm 0.21$ & $12.30 \pm 0.23$ \\
\hline 7 & $10.35 \pm 0.31$ & $11.28 \pm 0.20$ & $3.05 \pm 0.21$ & 17.880 .22 & $30.22 \pm 0.15$ & $30.44 \pm 0.24$ \\
\hline 8 & $24.26 \pm 0.20$ & $23.04 \pm 0.30$ & $18.41 \pm 0.13$ & $30.45 \pm 0.15$ & $40.18 \pm 0.22$ & $46.61 \pm 0.19$ \\
\hline 9 & $42.92 \pm 0.17$ & $42.24 \pm 0.14$ & $30.05 \pm 0.34$ & $40.59 \pm 0.16$ & $54.53 \pm 0.21$ & $61.30 \pm 0.22$ \\
\hline 10 & $61.50 \pm 0.26$ & $61.13 \pm 0.30$ & $48.69 \pm 0.31$ & $55.01 \pm 0.30$ & $63.88 \pm 0.16$ & $75.68 \pm 0.17$ \\
\hline 11 & $83.29 \pm 0.19$ & $81.79 \pm 0.20$ & $55.38 \pm 0.22$ & $73.85 \pm 0.19$ & $76.53 \pm 0.19$ & $82.53 \pm 0.25$ \\
\hline
\end{tabular}




\begin{tabular}{|c|c|c|c|c|c|c|}
\hline Time(hrs) & CF 7 & CF 8 & CF 9 & CF 10 & CF 11 & CF 12 \\
\hline 1 & $0.26 \pm 0.16$ & $0.35 \pm 0.29$ & $0.46 \pm 0.28$ & $0.74 \pm 0.17$ & $0.49 \pm 0.31$ & $0.49 \pm 0.39$ \\
\hline 2 & $0.39 \pm 0.22$ & $0.56 \pm 0.14$ & $0.59 \pm 0.16$ & $0.98 \pm 0.28$ & $0.77 \pm 0.28$ & $0.69 \pm 0.21$ \\
\hline 3 & $0.98 \pm 0.13$ & $1.21 \pm 0.30$ & $1.32 \pm 0.22$ & $1.35 \pm 0.34$ & $1.24 \pm 0.12$ & $1.04 \pm 0.42$ \\
\hline 4 & $1.44 \pm 0.42$ & $2.05 \pm 0.21$ & $2.14 \pm 0.34$ & $2.15 \pm 0.26$ & $2.16 \pm 0.22$ & $1.56 \pm 0.19$ \\
\hline 5 & $2.41 \pm 0.19$ & $2.65 \pm 0.26$ & $2.90 \pm 0.27$ & $2.94 \pm 0.20$ & $2.73 \pm 0.19$ & $2.27 \pm 0.24$ \\
\hline 6 & $3.06 \pm 0.28$ & $7.22 \pm 0.17$ & $8.11 \pm 0.19$ & $12.16 \pm 0.22$ & $12.57 \pm 0.31$ & $12.30 \pm 0.15$ \\
\hline 7 & $20.94 \pm 0.36$ & $18.19 \pm 0.13$ & $17.72 \pm 0.26$ & $27.26 \pm 0.12$ & $29.98 \pm 0.24$ & $29.74 \pm 0.21$ \\
\hline 8 & $30.26 \pm 0.17$ & $30.27 \pm 0.24$ & $30.40 \pm 0.34$ & $49.12 \pm 0.31$ & $49.24 \pm 0.27$ & $48.74 \pm 0.44$ \\
\hline 9 & $45.44 \pm 0.24$ & $52.06 \pm 0.28$ & $51.64 \pm 0.21$ & $61.22 \pm 0.17$ & $60.33 \pm 0.21$ & $59.72 \pm 0.17$ \\
\hline 10 & $63.86 \pm 0.31$ & $61.40 \pm 0.19$ & $61.59 \pm 0.39$ & $73.87 \pm 0.28$ & $74.16 \pm 0.32$ & $72.68 \pm 0.32$ \\
\hline 11 & $72.93 \pm 0.15$ & $81.13 \pm 0.22$ & $82.97 \pm 0.27$ & $90.93 \pm 0.43$ & $83.65 \pm 0.17$ & $82.99 \pm 0.26$ \\
\hline 12 & $90.23 \pm 0.24$ & $92.45 \pm 0.32$ & $92.18 \pm 0.43$ & $99.54 \pm 0.20$ & $97.74 \pm 0.25$ & $93.58 \pm 0.19$ \\
\hline
\end{tabular}

\section{References}

1. Rajendra Awasthi. Chronotherapy: Science and Technology of drug scheduling on the basis of Biological rhythm, Journal of Chronotherapy and Drug Delivery. 2010;1(1):9-18.

2. J Sajan, TA Cinu, AJ Chacko, J Litty and T Jaseeda. Chronotherapeutics and Chronotherapeutic Drug Delivery Systems. Tropical Journal of Pharmaceutical Research. 2009;8(5): 467-475.

3. Youan BIBC. Chronopharmaceutics: Science and Technology for Biological Rhythm-Guided Therapy and Prevention of Diseases. John Wiley \& Sons. Inc. 1-37.

4. Michael H Smolensky and Peppas NA. Chronobiology, drug-delivery and Chronotherapeutics. Adv Drug Deliv Rev. 2007;59(9-10):823851.

5. Karam F.Soliman, Elizabeth AM. Chronotoxicology. General, Applied and Systems Toxicology. 2009.

6. Devdhawala Mehul G. and Seth Avinash K. Current status of Chronotherapeutic drug delivery system: An overview. J Chem Pharm. Res. 2010;2(3):312-328.

7. B. Bruguerolle, G. Labrecque. Rhythmic pattern in pain and their chronotherapy. Adv Drug Deliv Rev. 2007;59(9-10):883- 895.

8. Vivek kumar pawar. Chronotherapy: An approach to synchronize drug delivery with circadian rhythm, Journal of Chronotherapy and drug delivery. 2010;1(1):1-8.

9. P. Srinivas. Chronotherapy-Clock of curing. International journal of pharma and biosciences. 2011;2(3):19-23.

10. Smolensky GE. Medical chronobiology: concepts and applications. Am Rev Respir Dis. 1993;147(6Pt 2):S2-19.

11.J. Cambar, M. Pons. New trends in Chronotoxicology in: P.H. Redfern, B. lemmereds Pharmacology. Volume 125. 557-588.

12. BB Youan. Chronopharmaceutics: gimmick or clinically relevant approach to drug delivery. J Controlled Release. 2004;98(3):344-345.

13. B Bruguerolle, G. Labrecque. Rhythmic pattern in pain and their chronotherapy. Adv Drug Deliv Rev. 2007;59 (9-10):883- 895.

14. Mandal AS1, Biswas N, Karim KM, Guha A, Chatterjee S, Behera M, et al. Drug delivery system based on chronobiology-A review. J Control
Release. 2010; 147(3):314-325.

15. PM Belanger, B Bruguerolle, G Labrecque. Rhythms pharmacokinetics: absorption, distribution, metabolism, and excreation: P.H.Redfer,B,Lemmer. Physiology and pharmacology of biological rhythms, Hand book of experimental pharmacology. 125.Spinger. Berlin. 1997. 177-204.

16. B Bruquerolle. Chronopharmacokinetics Current Status. Clin Pharmacokinet. 1998;35(2):83-94.

17. Rohit Bishit. Chronomodulated drug delivery system: A comprensive review on recent advances in new sub-discipline of chronopharmaceutics. Asian journal of pharmaceutics. 2011;5(1):1-8.

18. Pinar E, Terken B. Chronopharmacodynamics of drugs in toxicological aspects: A short review for clinical pharmacists and pharmacy practitioners. J Res Pharm Pract. 2012;1(2):41-47.

19. Rebecca A, Barbara M O'Brein. Uses of Misoprostol in Obstetrics and Gynecology. Rev Obstet Gynecol. 2009;2(3):159-168.

20. Bhupendra GP, Satish NP. Formulation, Evaluation and Optimization of Orally Disintegrating Tablet of Cinnarizine. e-journal of Science and Technology. 9-21.

21. Susan D’Souza. A Review of In Vitro Drug Release Test Methods for Nano-Sized Dosage Forms. Hindawi Publishing Corporation. Advances in Pharmaceutics. 2014;304757:1-12.

22. Takenaka H, Kawashima Y, Lin SY. Preparation of enteric-coated microcapsules for tableting by spray-drying technique and in vitro simulation of drug release from the tablet in GI tract. J Pharm Sci. 1980;69(2):1388-1392.

23. Karam F.Soliman, Elizabeth AM. Chronotoxicology. General, Applied and Systems Toxicology. 2009.

24.Akhan SE, Yidirim A, Iyibozkurt AC, Turfanda A. The evaluation of misoprostol-related tachysystole in normal and high risk pregnancies. Clin Exp Obstet Gynecol. 2000;27(3-4):207-211.

25. Rohit Mehta, Anuj C, Pooja Sharma, Pravin P. Formulation and in vitro evaluation of Eudragit S-100 coated naproxen matrix tablets for colon-targeted drug delivery system. J Adv Pharm Technol Res. 2013;4(1):31-41.

26. Bi-Botti CY. Chronopharmaceutical Drug Delivery Systems: Hurdles, Hype or Hope? Adv Drug Deliv. 2010;62(9-10):898-903. 